\title{
REVIEW
}

\section{Reticular formation and spinal cord injury}

\author{
D Wang \\ National Spinal Injuries Centre, Stoke Mandeville Hospital, Aylesbury, Buckinghamshire, UK
}

\begin{abstract}
Study design: Compact literature review to provide basic knowledge of the reticular formation (RF) for clinicians.

Setting: United Kingdom.

Materials and methods: The anatomical findings were collected from very recently published and well-edited books on neuroscience instead of hundreds of articles that contain materials still requiring test of time and difficult for busy clinicians to digest. Other individual references on specific issues such as a micturition centre, source of sildenafil citrate and so on are added. Clinical considerations discus commonly encountered problems of spinal cord injury service and science. Every clinical condition is discussed in conjunction with the anatomy and physiology of the RF.

Results: This section involves anatomy. (1) The core RF is located in the brain stem. The RF proper is divided into three longitudinal zones: the lateral (sensory), the medial (motor) and the midline (all others) zone. The midline zone is essential for wakefulness and consciousness. (2) Other brain stem structures sharing functions of the RF proper: periaqueductal grey (PAG), red nuclei, inferior olivary nucleus and precerebellar nucleus. PAG is almost related to all functions of the central nervous system, whereas the others are more connected to cerebellar functions of movements. (3) Spinal cord RF is located in the intermediolateral zone. It sends ascending and receives descending signals to coordinate and modulate motor, sensory and other functions.

Discussion: This section involves clinical consideration. Multisystem damage, muscle contraction, upper urinary tract, sexual behaviour, skin trophic, pain, sleep apnoea, cross-system damages, spinal cord repair and comprehensive management are discussed to enlighten the clinical importance of the RF.
\end{abstract}

Spinal Cord (2009) 47, 204-212; doi:10.1038/sc.2008.105; published online 26 August 2008

Keywords: reticular formation; multisynaptic connections; coordination and modulation; $\mathrm{SCl}$ complications; comprehensive management; spinal cord repair

\section{Introduction}

Reticular formation (RF) is an extremely important part of the human central nervous system (CNS). It offers basic support for life and health, without which diseases and complications inevitably occur and aggravate. Its destruction at high cervical level and above causes death. Despite its utmost importance, it is much less known, understood, taught and discussed than the somatic and autonomic systems.

Neuroscientists have spared no effort on studying it intensively and extensively for the past 50 years. A recent electronic search of references of the past 20 years using the keyword 'Reticular Formation' located around 3500 articles. It speaks volumes of the magnitude of its importance. This review has been undertaken to provide clinicians with some

Correspondence: Professor D Wang (retired), National Spinal Injuries Centre, Stoke Mandeville Hospital, 11 Selkirk Avenue, Aylesbury, Buckinghamshire, HP19 9QD, UK.

E-mail: dajue.wang@btopenworld.com

Received 8 April 2008; revised 19 June 2008; accepted 13 July 2008; published online 26 August 2008 basic knowledge of the RF without overloading them with too many neuroanatomical details.

After spinal cord injury (SCI), the following phenomena are observed in order of degree of threat to life and health.

1. Lack of wakefulness in high cervical lesions.

2. Malfunctions of viscerae and vascular systems.

3. Increased muscle tone (spasticity).

4. Hypersensitivity (pain).

5. Impairment and loss of sensation.

6. Impairment and loss of voluntary movement.

More often than not, the last two groups catch most attention of general public, patients and even biomedical professionals, because loss of voluntary movement and sensation is immediately visible and palpable, whereas understanding of the first four groups requires in-depth knowledge of their underlying neuroanatomy and neurophysiology, which may not be adequate for many people. Of the first four, the second group of phenomena is known to be 
related well to malfunctions of the autonomic systems. However, the regulating role of the RF is not sufficiently discussed.

No system works in isolation in a living organism. Even a simple contraction of a single muscle works in the following highly coordinative way.

1. Contraction needs a complex mechanism of sensory inputs to trigger it.

2. The contraction itself involves a series of complex physiological processes.

3. The antagonist muscle must relax.

4. The arterial supply must increase to transport more oxygen and nutrients to meet the energy needs.

5. The vein drainage must also increase to remove resultant extra metabolites.

Obviously, these can happen only when there is a central mechanism coordinating all these aspects with enormous complexity and accuracy. It is now known that the functions of the entire nervous system are controlled by a special part of the CNS known as the RF. It is the 'Command Centre' of the CNS. ${ }^{1}$ It controls the entire CNS through coordination and modulation, without which, the above-mentioned problems of SCI will inevitably occur. Unfortunately, such an important system of the human CNS is far from familiar to clinicians. This has prompted the need of this review.

\section{Materials and methods}

Anatomical findings are collected basically from some very recently published and well-edited books on neuroscience and SCI science instead of hundreds of articles that contain materials still requiring test of time and difficult for busy clinicians to digest. ${ }^{1-14}$ The rest are individual references. The discussion is based on common knowledge of the SCI scientific community in connection with anatomical findings of the RF. Clinical conditions such as multisystem damages, muscle contraction, lower urinary tract problems, skin trophic, pain, sleep apnoea, cross-system changes, spinal cord repair and comprehensive management as a whole are discussed in conjunction with the anatomical findings of the RF.

\section{Results}

\section{What is RF?}

Although the RF first received attention of Cajal ${ }^{15}$ as early as 1909, it had not been studied adequately until recently. Classical neuroanatomy focuses attention on neurons with one axon, one long tract, one synapse, one neurotransmitter and one target neuron. The RF is different. It is mostly composed of another type of neurons, known as the interneurons (neurons between neurons), that have polysynaptic connections (Figure 1). ${ }^{1,10}$ Each of these neurons has more than one axon, which go in different directions. Every interneuron connects with many secondary interneurons (primary connections). Many secondary neurons connect with even more interneurons (secondary connections).

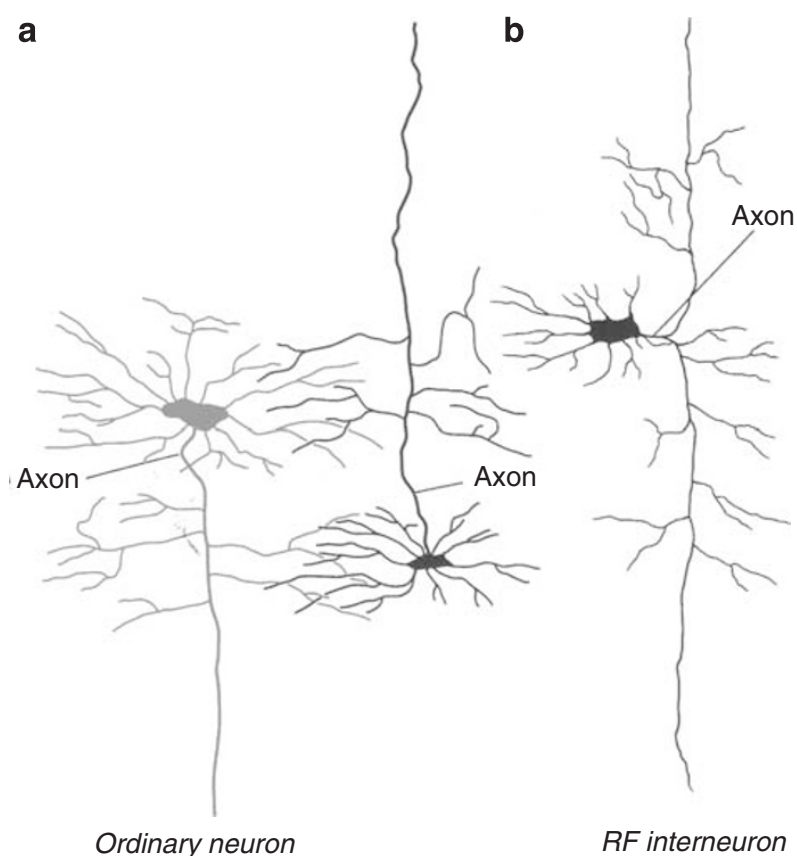

Figure 1 The difference between an (a) ordinary neuron and an (b) interneuron. The axons of the interneuron project in different directions. (Courtesy of Siegel A and Sapru HN. Essential Neuroscience. Lippincott Williams and Wilkins: Philadelphia, London, Tokyo, Hong Kong, 2006 $7-12$. The annotations in italics are the author's.)

This process goes on and the number of connections increases geometrically and finally reaches astronomical figures of more than trillions. These connections form a network-like system, hence the name RF. ${ }^{15}$

The astronomical number of connections of the RF has made complete severance of their connections almost impossible unless the relevant part of the CNS is completely destroyed. This is why the system can hardly be studied by traditional degeneration method. As a result, it had never been properly studied and understood until recently when new techniques such as electron microscopy, axon tracing, intracellular labelling, transmitter histochemistry, electrophysiology, advanced imaging and so on appeared during the past five decades. These techniques have immensely enhanced our knowledge of neuroanatomy, or more accurately, functional neuroanatomy.

In addition to the basic net-shaped multisynaptic interneuron connections, the RF has other distinct features. ${ }^{1,10}$

1. Its neurons are deeply located.

2. Its neurons are scattered and poorly defined and therefore it is difficult to name some small clusters of neurons as nuclei (Figure 2).

3. A single neuron may contain both ascending and descending components (Figure 1).

4. All its components contain crossed and uncrossed elements.

It is a misconception that neurons of the RF are located only in the brain stem. In fact, they also extend down through the entire length of the spinal cord. ${ }^{1}$ 
On account of the enormous difficulty in mapping out the exact pathways of trillions of interneuron connections, neuroscience has roughly worked out the destinations of the RF neurons by using advanced techniques. These techniques are able to locate both the action and the target neurons but the exact pathways between them may not be fully known. We are not discussing techniques that are not clinically directly relevant. Of the other techniques, electrostimulation has been a classical method for more than a century that does not need much discussion, whereas advanced imaging techniques are too complex to describe herein and important facts are still sketchy. However, there is already abundance of knowledge of neurotransmitters. ${ }^{2,7}$

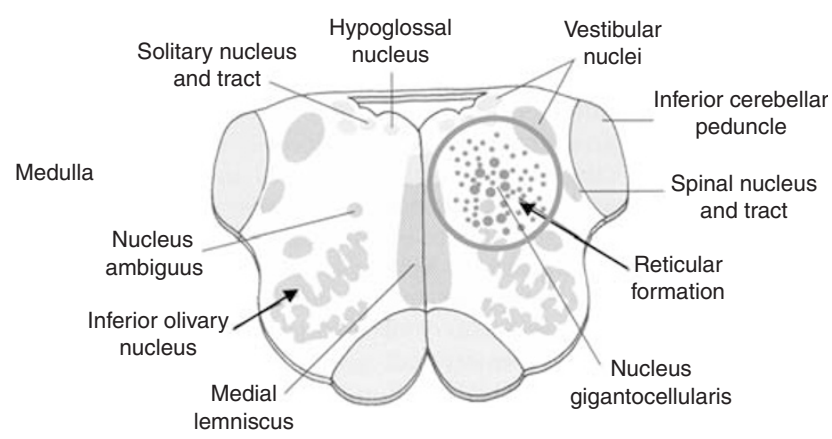

Figure 2 The disseminated locations of the RF neurons and the inferior olivary nuclei. (Courtesy of Patestas MA and Gardner LP. A textbook of neuroanatomy. Blackwell Publishing, $2006^{1-6}$. The arrows are the author's.) RF, reticular formation.

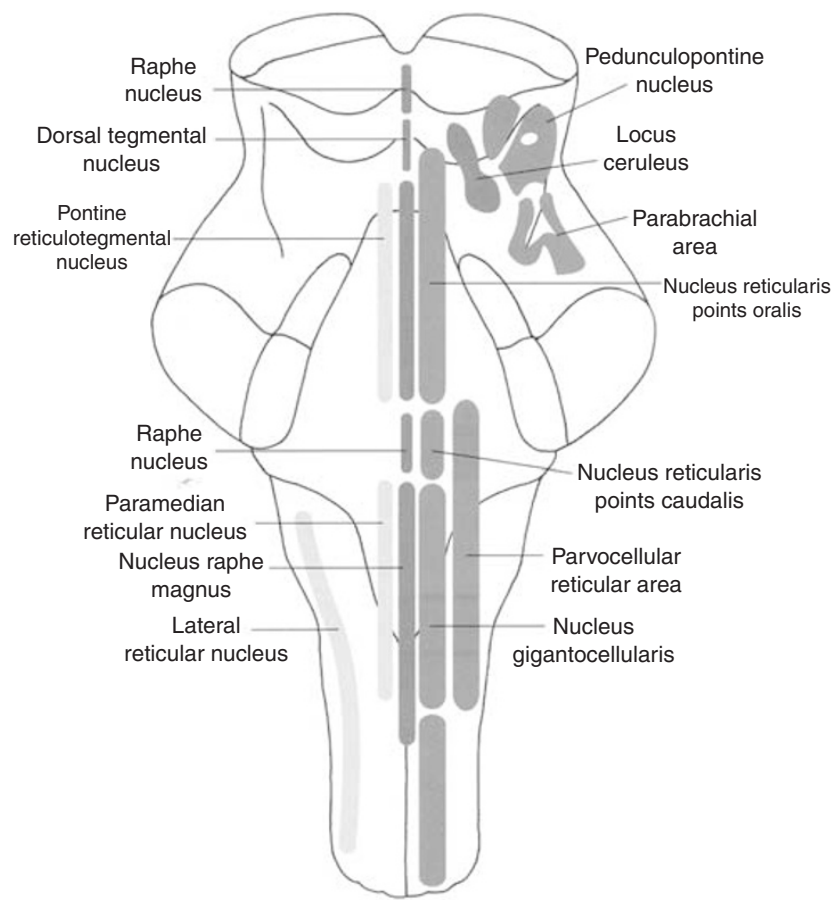

Figure 3 The longitudinal arrangement of zones of the brain stem RF. The most lateral strips on both sides are the lateral zones. Along the midline is the median or raphe zone. In between is the paramedian or the medial zone. (Courtesy of Patestas MA and Gardner LP. A textbook of neuroanatomy. Blackwell Publishing, $\left.2006^{1-6}\right) \mathrm{RF}$, reticular formation.
They are clinically highly relevant and merit special attention.

\section{Neurotransmitters}

Commanding adequate knowledge of neurotransmitters is a lifetime career for a specialist. Therefore, this review only offers a list of neurotransmitters for basic information (Table 1).

Neurotransmitters can also be hormones that are directly released into the blood stream and trigger neurons or other cells to work where there are relevant receptors. Thus, the classical distinction between neurotransmitters and neurohormones is blurred. It can be seen from the table that one area or one type of neuron may release more than one type of neurotransmitters whereas one type of neurotransmitter can be synthesized by more than one area or one type of neurons. Therefore, the strict rule of one type of neuron connected with one type of neurotransmitter is no longer valid.

\section{Basic morphology and functions}

The core of the RF is located in the brain stem with connections over the entire CNS. When Cajal ${ }^{15}$ introduced the term reticular formation in 1909 and even decades later, neuroscientists were not fully aware of its exact functions. Hence the name was solely based on morphology. In fact, there are other structures that are not net-shaped but share the functions of the RF of coordination and modulation. Functionally, they should be classified as one group that consists of three parts. ${ }^{1,10}$

1. Brain stem RF proper.

2. Regions in the brain stem that are closely related to RF: periaqueductal grey matter (PAG), red nucleus and inferior olivary nucleus. They cannot be named morphologically as RF because they are compact nuclei.

3. Spinal cord RF.

\section{Brain stem $R F$}

Complex connections between the RF and cranial nerves are not discussed herein because they are not major concerns of SCI. There is no need for clinicians to know all the complex names of individual RF nuclei. Knowledge of groups of neurons according to their longitudinal arrangements would suffice. These arrangements are in line with their functions and are hence easy to memorize. From the lateral aspect towards the midline, the nuclei of the RF and their functions are arranged in the following order (Figure 3).

1. Lateral: parvocellular (small cell) zone, afferent and sensory.

2. Paramedian and medial: magnocellular or gigantocellular (large cell) zone, efferent and motor.

3. Median or midline zone: raphe nuclei, wakefulness and consciousness.

Lateral zone. This area receives afferent fibres from neighbouring cranial nerves and the spinal cord through the spinoreticular tracts. The signals are in turn transmitted to 
Table 1 Classification and names of major neurotransmitters

\begin{tabular}{|c|c|c|}
\hline Description of neurotransmitters & Anatomical locations & Functions \\
\hline \multicolumn{3}{|l|}{ Small molecule } \\
\hline Acetylcholine & $\begin{array}{l}\text { Somatic and parasympathetic motor neurons, } \\
\text { myoneural junction, autonomic system and all major } \\
\text { regions of the CNS, including RF }\end{array}$ & $\begin{array}{l}\text { Muscle contraction, functions of the autonomic } \\
\text { system and all major regions of the CNS, } \\
\text { including RF }\end{array}$ \\
\hline \multicolumn{3}{|l|}{ Excitatory amino acids } \\
\hline Glutamate, precursor of GABA & Almost all regions of the CNS & Excitation, excitotoxicity $\rightarrow$ cell death. \\
\hline Aspartate & Almost all regions of the CNS & $\begin{array}{l}\text { Glutamate is stronger } \\
\text { than aspartate }\end{array}$ \\
\hline \multicolumn{3}{|l|}{ Inhibitory amino acids } \\
\hline GABA & Most parts of the CNS & Inhibition \\
\hline Glycine & All body fluids, spinal cord, lower brain stem, retina & Inhibition, intermediate in protein metabolism \\
\hline \multicolumn{3}{|l|}{ Biogenic amines } \\
\hline \multicolumn{3}{|l|}{ Catecholamines } \\
\hline Dopamine & Basal ganglia and limbic system & Muscle tone and mental status \\
\hline Norepinephrine & Sympathetic neurons, locus ceruleus of the pons & Mental status, exact mechanism unclear \\
\hline Epinephrine & Medulla & Not clear \\
\hline \multicolumn{3}{|l|}{ Indoleamine } \\
\hline $\begin{array}{l}\text { Serotonin } \\
\text { (5-hydroxytryptamine, }(5-\mathrm{HT}))\end{array}$ & Raphe or midline nuclei of the brain stem & Wakefulness and sleep \\
\hline \multicolumn{3}{|l|}{ Imidazole amine } \\
\hline Histamine & Hypothalamus & Endocrine and autonomic functions \\
\hline \multicolumn{3}{|l|}{ Purines } \\
\hline ATP & Spinal cord motor neurons, autonomic ganglia & Excitation \\
\hline Adenosine & Not fully investigated & Not fully understood \\
\hline \multicolumn{3}{|l|}{ Neuropeptides } \\
\hline \multicolumn{3}{|l|}{ Opioid peptides } \\
\hline$\beta$-endorphin & Spinal cord, hypothalamus & Pain suppressor \\
\hline Enkephalin & $\begin{array}{l}\text { Spinal cord, raphe nuclei, striatum, limbic system, } \\
\text { cerebral cortex }\end{array}$ & Major pain suppressor \\
\hline Dynorphin & Spinal cord, hypothalamus, amygdale, limbic system & Pain suppressor \\
\hline Nociceptin (Orphanin FQ) & Many locations in the brain and spinal cord & Pain enhancement and many others \\
\hline Substance P & $\begin{array}{l}\text { Trigeminal and dorsal ganglia, spinal cord, } \\
\text { hippocampus, neocortex }\end{array}$ & Pain transmission \\
\hline \multicolumn{3}{|l|}{ Gaseous neurotransmitter } \\
\hline Nitric oxide & Hippocampus and many other regions of the brain & $\begin{array}{l}\text { Memory, wakefulness and sleep, neuroprotective } \\
\text { to neurotoxic and many more. New discoveries } \\
\text { are emerging fast }\end{array}$ \\
\hline
\end{tabular}

Abbreviations: CNS, central nervous system; GABA, $\gamma$-amino-butyric acid; RF, reticular formation.

the paramedian or medial zone to modulate motor functions. Other collaterals ascend to the thalamus to modulate sensation or project to other higher centres (hypothalamus, limbic system) through the median zone to sustain wakefulness and to modulate autonomic functions.

Paramedian or medial zone. Neurons of this zone have reciprocal connections with almost all movement-related structures of cerebral cortex, diencephalons, basal ganglia, cerebellum and spinal cord. These connections contribute to the coordination of both voluntary and involuntary movements and adjustment of muscle tone. A special group of large cells, known as the nucleus gigantocellularis, gives rise bilaterally to medullary (lateral) reticulospinal tract. It suppresses extensor spinal reflexes to the spinal motor neurons. Two other groups of cells known as nucleus pontis oralis and nucleus pontis caudalis project ipsilaterally to the spinal cord motor neurons and facilitate extensor spinal reflexes. The tract is named pontine (medial) reticulospinal tract. ${ }^{1,3,8,10}$ The balance between inputs of the two tracts keeps the normal muscle tone in movement.

Median or midline zone. There are two basic types of neurons.

1. Serotoninergic neurons project to higher centres and are crucial to wakefulness and sleep. Damage to these neurons or lack of inputs may lead to diminished or loss of consciousness.

2. Other neurons that synthesize enkephalin and $\beta$-endorphin project downwards to both spinal trigeminal nuclei 


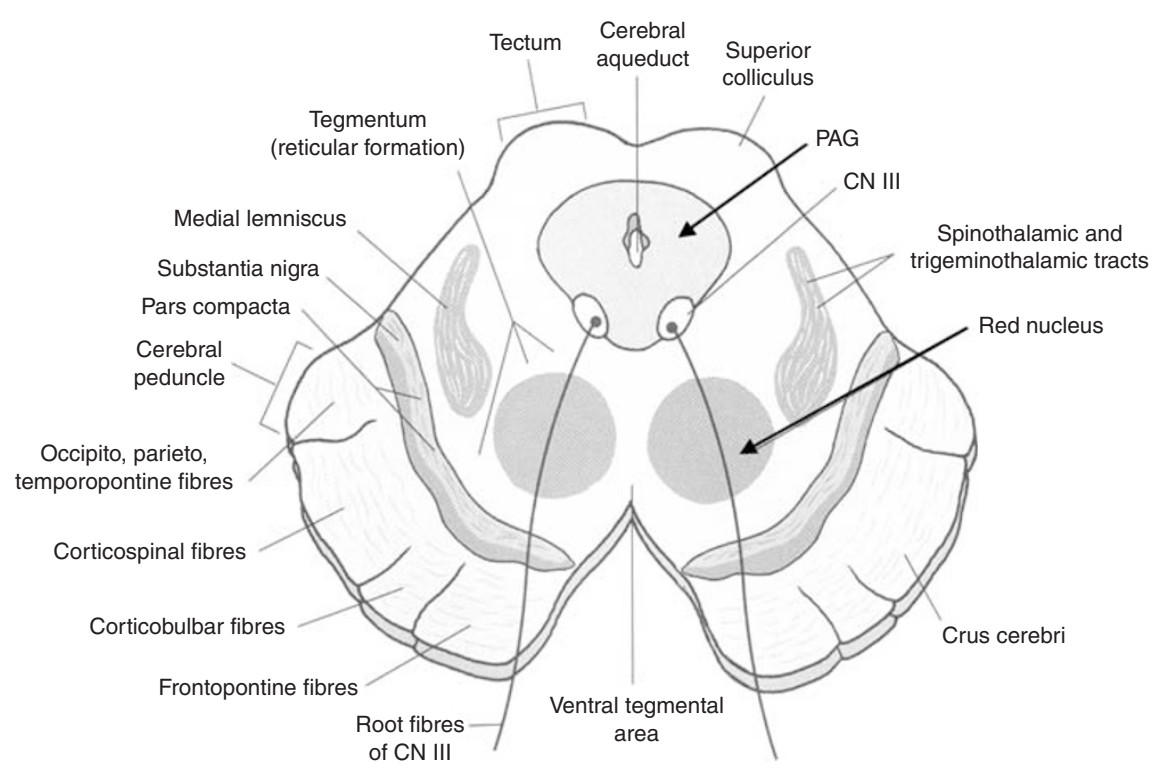

Figure 4 The periaqueductal grey (PAG) and the red nuclei. (Courtesy of Patestas MA and Gardner LP. A textbook of neuroanatomy. Blackwell Publishing, $2006^{1-6}$. The arrows are the author's.)

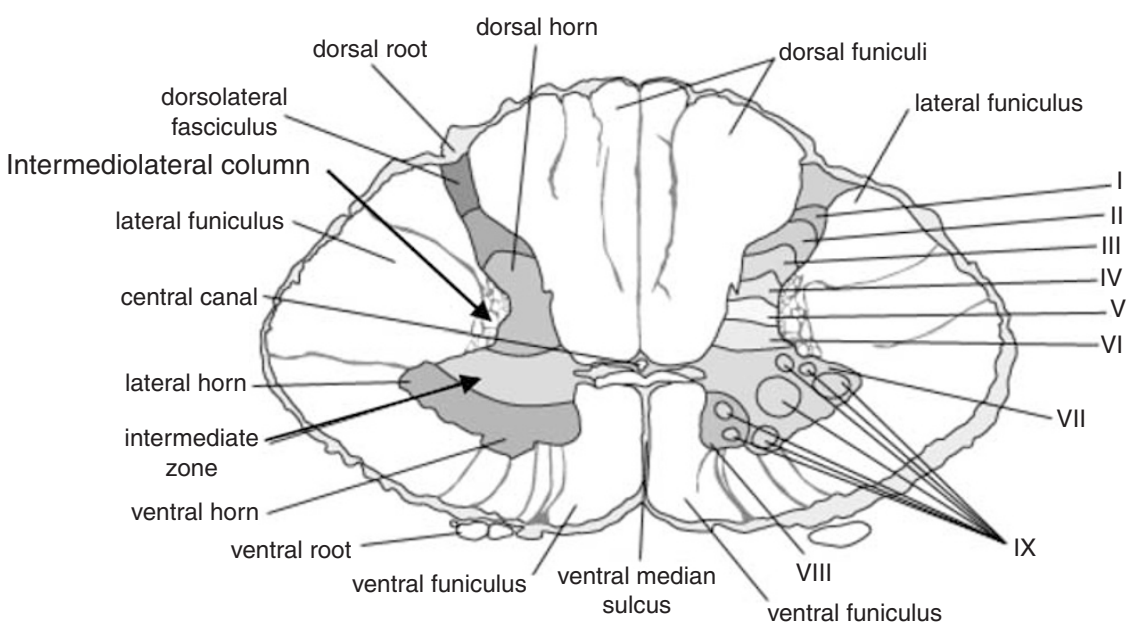

Figure 5 Cross-section of the spinal cord to show the intermediate zone (RF) and the intermediolateral column (autonomic systems). (Courtesy of Encyclopedia Britannica, 2007. The arrows and the annotation of intermediolateral column are the author's.) RF, reticular formation.

and spinal dorsal horn nuclei to modulate and suppress nociception.

\section{Other RF-related brain stem areas}

Periaqueductal grey matter has reciprocal connections with cerebral cortex, hypothalamus, limbic system, RF nuclei within the brain stem and the spinal cord (Figure 5). Such extensive connections indicate its extremely important role of coordinating and modulating functions of the autonomic and endocrine systems, emotion, memory and nociception. Its neurons project to spinal cord through magnocellular zone of pons and medulla. Recent studies have shown that they might also send signals directly to the spinal cord. Of these pathways, much attention has been focused recently on micturition control. ${ }^{16-18}$ It remains to be seen if it is more important than the pons micturition centre (Barrington nuclei). ${ }^{19}$ In a combination of all its connections, PAG could be the most important processing centre of all signals except those from the red nucleus motor system for skilled movements of upper limbs.

Red nucleus projects to cerebellum through inferior olivary nucleus and precerebellar nucleus (Figures 2 and 4). Red nucleus has reciprocal connections with both motor cortex and cerebellum. Its final common path after cerebral and cerebellar inputs is the rubrospinal tract. It is highly developed in lower animals such as, cat but reduced to a thin tract below cervical level in humans, in which it mainly discharges flexor muscles of the upper limb. 


\section{Spinal cord $R F$}

Neurons of the spinal cord RF are located in the intermediate zone of the grey matter (Figure 5). It should not be confused with the intermediolateral (lateral) column, which contains preganglionic neurons of the autonomic (sympathetic and parasympathetic) system. ${ }^{1}$ The intermediate zone is continuous with the lateral zone of the brain stem RF. Its neurons give rise to the spinoreticular tract. Neurons of the intermediolateral column of the autonomic system receive inputs from the RF through reticulospinal tracts or from the PAG through the tectospinal tract. 1,3,8,10

The dorsal horn does not belong to the RF but it receives important inhibitory inputs from brain stem RF and PAG to suppress pain also through the reticulospinal tracts..$^{3,8}$

The reticulospinal tracts synapse with interneurons of the intermediate zone or in a lesser extent directly with motor neurons. They send signals to coordinate and modulate muscle activities, tone and reflexes between various muscle groups. $1,3,8,10$

The spinothalamic tract is now known to contain two parts. ${ }^{6,9}$ One is the neospino-thalamic tract whereas the other is the paleospinothalamic tract. The former is phylogenetically new and belongs to the somatosensory system and its fibres cross to the contralateral side. It is the direct pathway conducting nociceptive stimuli to the thalamus. The latter is phylogenetically ancient and belongs to the RF. It is both ipsilateral (major part) and contralateral (minor part). The paleospinothalamic tract ascends to the brain stem RF and through it back to the spinal cord to modulate its sensory inputs.

\section{Discussion}

This section is about clinical considerations based on the anatomical facts described above. As RF is closely connected to all parts of the CNS, it is impossible to describe and discuss all dysfunctions caused by its damage in one paper. Hence, only major clinical problems in SCI are dealt with herein.

\section{Multisystem damages}

Spinal cord injury is a transverse lesion that cuts off longitudinal connections between higher centres of the CNS and the spinal cord. Hence, its special feature is the breakdown of coordination and modulation by higher centres of various parts below the lesion rather than isolating malfunctioning of any individual part. Hence, as a rule, SCI is a lesion of multisystem damages. The uncoordinated and unmodulated spinal reflex below the lesion causes serious problems. Following are some examples.

\section{Muscle contraction}

In case of upper neuron damage, muscles below the lesion contract in response to incoming stimuli through spinal reflex as there is no voluntary and RF inputs to trigger, control, coordinate and modulate the muscle. Muscles contract in response to inputs through spinal reflex involuntarily without proper power, tone, range and frequency. Such untoward muscle contractions are known as spasms. Damages of the RF compromise or abolish the prevailing inhibitory inputs from the reticulospinal tracts to the spinal motor neurons, leading to hypertonicity and spasticity. ${ }^{1,3,8,10}$

The lower urinary tract (LUT)

The LUT is unique for many reasons.

1. It is innervated by the lowest segments (S2-4) of the spinal cord. Hence, whatever the level of injury, it is affected. This means that almost every patient with sufficient damage at any level will have a urological problem. It creates a serious problem among a large population. According to Stoke Mandeville Hospital Clinical Database, more than 70\% of the outpatients are urological, and renal failure, as a result of urological complications, is the no. 1 cause of death in developing countries. ${ }^{20}$

2. Urological problem is a protracted chronic condition that needs constant long-term attention.

3. It also affects sexual functions.

4. It is highly disadvantaged by lacking vagus innervation and biochemical regulation (blood $\mathrm{CO}_{2}$ and $\mathrm{O}_{2}$ ) of the cardiorespiratory system and the intramural innervation of the bowel that make these system relatively manageable while LUT more vulnerable.

5. Urine is a fluid difficult to handle. Flow in the wrong direction and wrong time, at the wrong temperature, under the wrong pressure and containing wrong substances all can cause huge health and social problems.

Spinal cord injury patients present with various types of neuropathic bladder of enormous complexity. The typical example of breakdown of coordination and modulation is detrusor-sphincter dyssynergia. ${ }^{21}$ Neurourology was established to study and resolve the problems by replacing the missing role of coordination and modulation. This can be achieved through mechanical (catheterization, stent) or pharmaceutical (mostly using pro- or antineurotransmitter substances) means, electrical stimulation (sacral anterior root stimulation), surgery (sphincterotomy), prosthesis (artificial sphincter) or these methods in various combinations.

\section{Sex behaviour}

Sex behaviour is a complex psycho-neuro-endocrinological process. Among the other systems (visual, auditory, olfactory and so on) at the centre of neuroendocrinology are the hypothalamus and the brain stem RF, particularly the PAG. ${ }^{5,11}$ After SCI, psychogenic sexual behaviour does not take place below the lesion. However, the reciprocal impact between the hypothalamus and the PAG remains. This will regulate the release of gonadotropin and in turn the sexual emotion and related physical behaviour above the lesion like touching, hugging and kissing. Below a complete lesion in the sense not only of somatic systems but also RF, sexual act is compromised. In sexual acts, males play a more active role. In an upper neuron lesion, reflex erection may still exist, whereas in a lower neuron lesion it is impossible. A decade and so ago, a chemical known as sildenafil citrate was proven 
to facilitate erection at spinal level. ${ }^{22}$ Its vasodilating effect depends upon nitric oxide, a neurotransmitter synthesized in PAG. ${ }^{23}$ Its effect varies with individuals subject to the match of receptors within the autonomic system at sacral level.

\section{Skin trophic}

External mechanical pressure for a considerable length of time $(>2 \mathrm{~h})$ on the skin causes sores to develop in SCI persons. The underlying human factors are anatomical and pathophysiological. The key to maintaining normal skin trophic is its blood supply, in which arterioles and venules play a pivotal role. Both of them have smooth muscles in their walls to respond to the need of blood supply. The more vulnerable part is the venules. They have thinner and weaker smooth muscle layers and hence are more susceptible to pressure. The lumen becomes more or less flat and blood flow is restricted under pressure. This causes venous stasis. In a normal individual, the situation will trigger a very complex mechanism involving many local substances. Some of the substances are vasoconstrictors (epinephrine, $\mathrm{Ca}^{++}$), whereas the others are vasodilators (acids, $\mathrm{CO}^{2}$, low $\mathrm{O}^{2}$, potassium, acetylcholine, bradykinin, adenosine, nitric oxide and so on). The whole complex of opposing mechanisms is regulated by the RF to achieve a net result of dilation. The arterioles and the precapillary sphincters open more widely to allow more blood to push through the capillaries and boost up the venules. When the RF is broken down, optimal net result of vasodilatation does not occur and venous stasis and arterial hypoxaemia ensue leading to pressure sore. ${ }^{13,14}$

\section{Pain}

Pain is a normal perception (nociceptive pain) of human selfdefense mechanism. When an individual feels the pain of a wound or an ailment, the pain is normal. It reminds him or her of the existence of the wound or ailment that he or she should take care of. Only when there is no obvious internal or external cause and the pain persists, or when the pain becomes disproportionately frequent and severe, it becomes a pathological pain on its own (neuropathic pain).

Neuropathic pain is the main concern in SCI. Many pains are difficult to explain by somatosensory pathways. However, it can be explained in the perspective of the RF by its multisynaptic connections that cannot be totally destroyed. They can become alternative pathways conducting pain. Also, cutting of RF's role of modulation and release of nociceptin (Orphanin FQ) can aggrevate pain. ${ }^{2,6,7,9}$

In the spinal cord, there is a gate control mechanism of presynaptic inhibition of pain at the Substantia Gelatinosa Zone II before it gives rise to secondary neurons and spinothalamic tract. ${ }^{6,9,24}$ The secondary neurons also receive inhibitory influence from the brain RF to modulate pain. Of them, the strongest probably comes from the PAG.

Acupuncture and electrical stimulation of $A \alpha$ and $A \beta$ fibres to reduce pain are exactly based on this Gate Control hypothesis together with descending inhibitory impulses from the brain stem RF. Acupuncture and electrical stimulation also prompt release of opiate-like neurotransmitters or neurohormones (opioid peptides).

The current definition of completeness of SCI is based on somatic systems. It does not mean complete damage to the RF. Therefore, even in the so-called complete injury, nonpainful stimuli below and at the level of injury can be misperceived as pain and get through via the RF to reach higher levels of the CNS. In incomplete injury, the picture is even more so. Pain perception is not just about peripheral and ascending inputs. It is also about central modulation by the brain stem RF. Apart from sensory inputs from thalamus and sensory cortex, the brain stem RF has connections with structures related to emotion, memory, endocrine and metabolic regulation from the cortex, limbic system and hypothalamus. It has an important function in modulating pain in either direction. Increase of modulation can suppress pain whereas its decrease can aggravate it.

A very important recent development in the understanding of neuropathic pain is the relation between pain and memory. ${ }^{25}$ It could be a key mechanism of central pain and may well explain why the pain persists while peripheral noxious stimuli do not seem to exist because memory of pain is still there. Such a mechanism could be associated with the RF that has close connections with pain, memory and emotion.

\section{Sleep apnoea}

Sleep apnoea is a rare but fatal condition if not reversed timely. In high cervical lesions, blood oxygen can become dangerously low due to extremely shallow breathing during sleep. Insufficient afferent impulses to the brain stem RF and higher centres as a result of high level of paralysis deprive the individual's ability of waking up and restoring normal rhythm of respiration. The patient may stop breathing altogether and die while asleep. ${ }^{1,10}$

\section{Cross-system changes}

Owing to the wide connections of the RF throughout the CNS, any stimulus from one system could affect another. ${ }^{26}$ In SCI, the clear examples are that stimuli from the skin (uncomfortable temperature, pressure sore) and the bladder (calculus, infection and so on) can trigger and increase spasm and spasticity. On the other hand, high intravesical pressure can trigger dysreflexia. There could be many more such changes, which are chronic and may not be as obvious as the above-mentioned changes. Hence, further detailed observation and investigations are necessary to exploit and prevent the not yet known cross-system damages.

\section{Spinal cord repair and functional recovery}

Spinal cord repair has come to an age of clinical trial. Some work has been done around the world. The assessment of the results of the trial depends upon outcome measure. Most clinicians involved in the research expect major return of somatomotor and somatosensory functions as the most important criteria.

As one of the most renowned evolutionary biologists, Theodosius Dobzhansky (1973) wisely pointed out, 'Nothing 


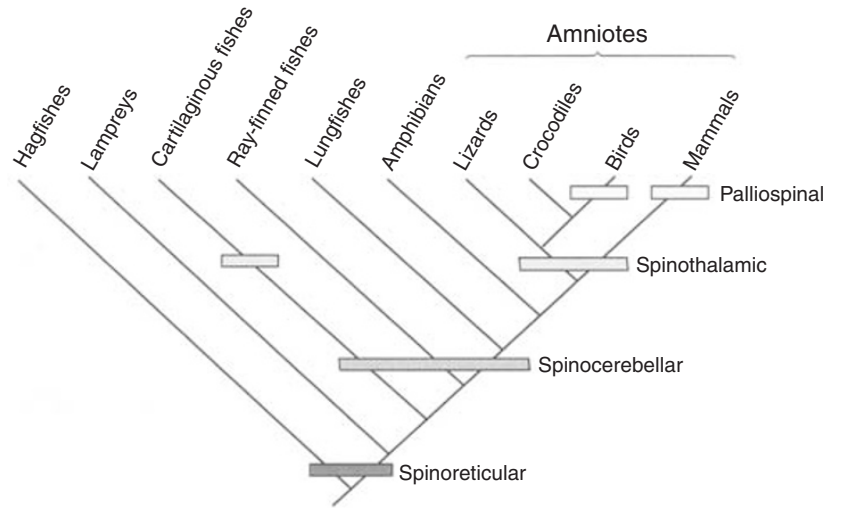

Figure 6 The phylogenetic order of development of the CNS. (Courtesy of Northcutt RG. Evolution of the vertebrate central nervous system: patterns and processes. Ann Zool 1984; 24: 701-716)

in biology makes sense except in the light of Evolution.'27 Hence, such expectations have to be judged from an evolutionary point of view. We are in the very early stage of understanding how spinal cord repair can be achieved with transplant of more or less primitive cells. Therefore, we cannot expect to achieve somatomotor and somatosensory functions to recover satisfactorily because these systems are relatively late phenomena in the ladder of phylogenetic evolution. ${ }^{28}$ The most ancient systems in the human CNS are olfactory system, limbic system and RF. Cells from these systems have more powerful ability to repair or to be repaired. In case spinal cord is to be repaired, the RF is more relevant because the other two systems exist only in the brain. Moreover, the RF is rarely completely damaged. This offers good opportunities for it to be structurally repaired or at least to achieve some functional recovery.

The phylogenetic order of development of various parts of the human CNS from bottom up is (Figure 6): ${ }^{29}$

1. Somatomotor system.

2. Somatosensory system.

3. Cerebellar system.

4. RF.

Hongyun Huang from China has done olfactory ensheathing cell transplantation for SCI on hundreds of chronic SCI patients. ${ }^{30}$ The limited observation of 60 patients shortly after the transplantation by the author of this review gave him the impression that the pattern of recovery followed the above-mentioned order; that is, skin temperature, spasticity and bladder function, which are closely connected to the RF, improved first followed by somatosensory and somatomotor recovery to a much lesser extent. There is difficulty in assessing cerebellar functions when the muscle power is too weak. Such impression is not conclusive, and much stricter and well-organized clinical trial is needed before any solid conclusion can be drawn.

\section{Comprehensive management}

If there is a transverse lesion above high cervical level severely damaging the RF bilaterally, the patient cannot survive because of complete cardiac and respiratory failure and loss of consciousness. These functions are all heavily controlled by the RF. Those who survive this level of injury must have only localized lesions that cause mild-to-moderate damages to the RF so that sufficient cardiac and respiratory functions and consciousness remain.

With a severe transverse lesion from mid cervical level down, the RF supporting cardiac and respiratory functions and consciousness escapes destruction. The patients can survive but suffer from serious malfunctioning of organs below the lesion. These patients are the most complex and complicated of all surviving patients with nervous lesions. The explanation is simple. As just mentioned, patients above this level just die and are not seen by clinicians. Thinking that patients with spinal cord lesions must be less complex and complicated than those with brain lesions and hence SCI science is technologically inferior to brain neuroscience is a misperception.

In SCI, there is always multisystem malfunctioning. During Sir Ludwig Guttman's time, the morphology and functions of the RF was not fully investigated and understood. However, his clinical observations and understanding of SCI were totally in line with facts and theory of modern neuroanatomy about RF. This was why he successfully developed the system of comprehensive management that dealt with all aspects of SCI in a non-fragmented way under one roof. ${ }^{14}$ The entire management was aiming at resuming some sort of coordination and modulation either within the nervous system or at the peripheral organs. This comprehensive approach to management has saved the life of many SCI patients. Now, the causes of death among individuals with SCI begin to approximate the causes of death of the non-disabled population. ${ }^{31}$

For the last two decades or so, there have been massive advances of biomedical technologies. These technologies have improved SCI service and science immensely. As a result, some specialists begin to think that they can work on their own, and coordination (collaboration) is not as important as it was during Guttmann's era. Such a perception misses an important point. Although biomedical technologies have advanced tremendously, the basic neuroanatomy and neurophysiology have not changed a bit. It still requires the CNS to work in a coordinative and modulatory way. However high the individual technology, without coordination and modulation, the SCI management will fail.

\section{Conclusions}

The RF has multisynaptic connections with all parts of the CNS. It controls all functions through coordination and modulation. In SCI, such coordination and modulation are broken down and hence the injury is always associated with multisystem damages. Only comprehensive management can help.

\section{References}

1 Patestas MA, Gartner LP. Chapter 14. Reticular formation. In: Patestas MA, Gartner LP (eds). A Textbook of Neuroanatomy. Blackwell Publishing: Malden, Oxford, Carlton, 2006, pp 241-252. 
2 Patestas MA, Gartner LP. Chapter 4. Neurotransmitter substances. In: Patestas MA, Gartner LP (eds). A Textbook of Neuroanatomy. Blackwell Publishing: Malden, Oxford, Carlton, 2006, pp 44-53.

3 Patestas MA, Gartner LP. Chapter 5. Spinal cord. In: Patestas MA, Gartner LP (eds). A Textbook of Neuroanatomy. Blackwell Publishing: Malden, Oxford, Carlton, 2006, pp 54-67.

4 Patestas MA, Gartner LP. Chapter 20. Limbic system. In: Patestas MA, Gartner LP (eds). A Textbook of Neuroanatomy. Blackwell Publishing: Malden, Oxford, Carlton, 2006, pp 344-360.

5 Patestas MA, Gartner LP. Chapter 21. Hypothalamus. In: Patestas MA, Gartner LP (eds). A Textbook of Neuroanatomy. Blackwell Publishing: Malden, Oxford, Carlton, 2006, pp 361-384.

6 Patestas MA, Gartner LP. Chapter 10. Ascending sensory pathways. In: Patestas MA, Gartner LP (eds). A Textbook of Neuroanatomy. Blackwell Publishing: Malden, Oxford, Carlton, 2006, pp 137-170.

7 Siegel A, Sapru HN. Part 8, Neurotransmitters. In: Siegel A, Sapru HN (eds). Section II The Neuron. Essential Neuroscience. Lippincott Williams and Wilkins: Philadelphia, London, Tokyo, Hong Kong, 2006, pp 105-132.

8 Siegel A, Sapru HN. Section III. Organization of the central nervous system. In: Siegel A, Sapru HN (eds). Essential Neuroscience. Lippincott Williams and Wilkins: Philadelphia, London, Tokyo, Hong Kong, 2006, pp 133-252.

9 Siegel A, Sapru HN. Part 15, Somatosensory system. In: Siegel A, Sapru HN (eds). Section IV The Neuron. Essential Neuroscience. Lippincott Williams and Wilkins: Philadelphia, London, Tokyo, Hong Kong, 2006, pp 255-267.

10 Siegel A, Sapru HN. Part 23, The reticular formation. In: Siegel A, Sapru HN (eds). Section VI The Integrative Systems. Essential Neuroscience. Lippincott Williams and Wilkins: Philadelphia, London, Tokyo, Hong Kong, 2006, pp 408-426.

11 Siegel A, Sapru HN. Part 24, The hypothalamus. In: Siegel A, Sapru HN (eds). Section VI The Integrative Systems. Essential Neuroscience. Lippincott Williams and Wilkins: Philadelphia, London, Tokyo, Hong Kong, 2006, pp 427-444.

12 Siegel A, Sapru HN. Part 25, The limbic system. In: Siegel A, Sapru HN (eds). Section VI The Integrative Systems. Essential Neuroscience. Lippincott Williams and Wilkins: Philadelphia, London, Tokyo, Hong Kong, 2006, pp 445-464.

13 Kapit W, Macey RI, Meisami E. Part 43, Local and systemic control of small blood vessels. In: Kapit W, Macey RI, Meisami E (eds). Section Circulation. The Physiology Colouring Book, 2nd edn. Addison Wesley Longman, Inc.: San Francisco, New York, Harlow, Sydney, Amsterdam, 2000, p 43 (two facing pages).

14 Guttmann L. Spinal Cord Injuries: Comprehensive Management and Research (2nd edn). Blackwell Science Ltd: Oxford, London, Edinburgh, Victoria, 1973.

15 Cajal S RY. Histologie du Systeme Nerveux de L'homme et des Vertebres. Institute Cajal: Madrid, 1909.
16 Blok BF, Holstege G. Direct projections from the periaqueductal gray to the pontine micturition centre M-region. An anterograde and retrograde tracing study in the cat. Neurosci Lett 1994; 166: 93-96.

17 Blok BF, Willemson A-T, Holstege G. A PET study on brain control of micturition in humans. Brain 1997; 120: 111-121.

18 Blok BF, Sturms LM, Holstege G. Brain activation of micturition in women. Brain 1998; 121: 2033-2042.

19 Barrington FJF. The relation of the hind-brain to micturition. Brain 1924; 43: 23-53.

20 Yuan H, Hao D, Liu J, Yuan F, Wang D. A follow-up study on longterm complications and mortality of spinal cord injury patients. Abstract presented at the 42nd ISCoS Annual Scientific Meeting Beijing 2003.

21 Guy P, Grundy D. Chapter 7. Medical management in the spinal injuries unit. In: Grundy D, Swain A (eds). ABC of Spinal Cord Injury. BMJ Publishing Group: London, 2002, pp 33-40.

22 Maytom MC, Derry FA, Dinsmore WW, Glass CA, Smith MD, Orr $\mathrm{M}$ et al. A two-part pilot study of sildenafil $\left(\right.$ Viagra $\left.^{\mathrm{TM}}\right)$ in men with erectile dysfunction caused by spinal cord injury. Spinal Cord 1999; 37: 110-116.

23 Patel D, Chaitoff KA, Nolan A, Bohlke M, Maher TJ, Ally A et al. Endothelial nitric oxide synthase (eNOS) within the periaqueductal gray matter differentially modulates neurotransmission and cardiovascular response during mechanical, heat and cold nociception. FASEB J 2008; 22: 1154.16.

24 Melzack P, Wall PD. Pain mechanisms: a new theory. Science 1965; 150: $171-179$.

25 Millecamps M, Centeno M, Berra H, Rudick CN, Lavarello S, Tkatch $\mathrm{T}$ et al. d-Cycloserine reduces neuropathic pain behavior through limbic NMDA-mediated circuitry. Pain 2003; 132: 108-123.

26 Grundy D, Tromans A, Carvell J, Jamil F. Chapter 6. Medical management in the spinal injuries unit. In: Grundy D, Swain A (eds). ABC of Spinal Cord Injury. BMJ Publishing Group: London, 2002, pp 25-32.

27 Dobzhansky T. Nothing in biology makes sense except in the light of evolution. American Biology Teacher 1973; 35: 125-129.

28 Striedter GF. Chapter 2. A history of comparative neurobiology. In: Striedter GF (ed). Principles of Brain Evolution. Sinauer Associates, Inc. Publishers: Sunderland, Massachusetts, USA, 2005, pp 10-50.

29 Northcutt RG. Evolution of the vertebrate central nervous system: patterns and processes. Ann Zool 1984; 24: 701-716.

30 Huang H. Chapter 7. Olfactory ensheathing cell transplantation for the treatment of chronic SCI patients. In: Huang $\mathrm{H}$ (ed \& author) Olfactory Ensheathing Cell Transplantation. Scientific Press: Beijing, 2007, pp 117-187 (Chinese).

31 Whiteneck GG. Chapter 3. Learning from recent empirical investigations. In: Whiteneck GG et al. (eds). Aging with Spinal Cord Injury. Demos: New York, 1993, pp 23-37. 